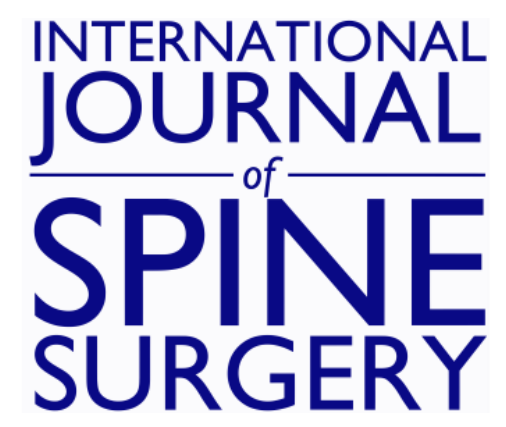

\title{
Rare case of conus medullaris syndrome from a metastatic yolk sac tumor originating from the mediastinum of an adult male: a case report and review of the literature
}

Remi M. Ajiboye, Scott D. Nelson and Arya N. Shamie

Int J Spine Surg 2015, 9 ()

doi: https://doi.org/10.14444/2059

http://ijssurgery.com/content/9/59

This information is current as of April 26, 2023.

Email Alerts Receive free email-alerts when new articles cite this article. Sign up at:

http://ijssurgery.com/alerts

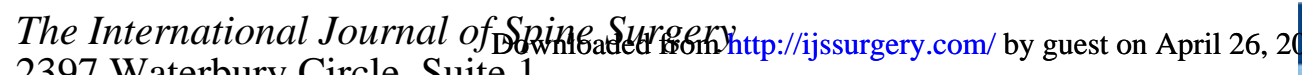
2397 Waterbury Circle, Suite 1,

Aurora, IL 60504, Phone: +1-630-375-1432 


\section{Rare case of conus medullaris syndrome from a metastatic yolk sac tumor originating from the mediastinum of an adult male: a case report and review of the literature}

Remi M. Ajiboye, MD, Scott D. Nelson, MD, Arya N. Shamie, $M D$

UCLA Medical Center, Department of Orthopaedic Surgery, Los Angeles, CA

\section{Abstract}

Background

Yolk sac tumors (YST) are malignant neoplasms. They are a subtype of germ cell tumors and typically originate in the gonads although extragonadal origins of such tumors have been described. Yolk sac tumors are commonly found in the gonads of infants and children and are extremely rare in adults. The goal of this case report is to describe the clinical presentation of a rare case of metastatic extragonadal yolk sac tumor originating from the mediastinum and causing an acute conus medullaris syndrome in an adult male.

\section{Methods}

A 47-year old male presented to our emergency department with a one-day history of bilateral lower extremity weakness, urinary retention and bowel incontinence. Imaging revealed a destructive lesion and a burst fracture of the first lumbar vertebral body (L1) with severe spinal canal stenosis. An urgent spinal decompression and fusion was performed. Oncologic workup revealed a yolk sac tumor originating from the mediastinum.

Results

His neurologic function, including motor strength, bowel and bladder function improved in the postoperative period. Chemotherapy regimen of ifosfamide, etoposide and cisplatin was administered and radiation therapy was administered to the spine tumor bed.

\section{Conclusions}

Yolk sac tumors, although rare, should be considered in the long list differential diagnosis of an otherwise healthy male presenting with conus medullaris or spinal cord compression from metastatic disease without evidence of a testicular mass. Prompt diagnosis with urgent decompression of neural structures and stabilization of the spine may result in improvement in neurological function.

KEYWORDS: YOLK SAC TUMOR, GERM CELL TUMOR, CONUS MEDULLARIS SYNDROME, CORD COMPRESSION, PATHOLOGIC FRACTURES

VOLUME 9 ARTICLE 59 DOI: 10.14444/2059

\section{Introduction}

Yolk sac tumors (YST) are malignant neoplasms. They are a subtype of germ cell tumors. Germ cell tumors occur primarily in the gonads. In $1-5 \%$ of cases, these tumors originate in some specific extragonadal sites (notably midline structures from the pineal gland to the coccyx). ${ }^{1,2}$ Yolk sac tumors are commonly found in the gonads of infants and children and are rare in adults. ${ }^{3}$ In this article, we describe the case of an extragonadal yolk sac tumor originating from the mediastinum and presenting as a burst fracture with acute cord compression in an adult male.

\section{Case Report}

\section{History}

A 47-year-old male with no past medical history was in his usual state of health when he presented to the Emergency Room (ER) with a one-day history of sudden-onset of bilateral lower extremity weakness, back pain, saddle anesthesia, urinary retention and loss of bowel function. 


\section{Examination}

On examination, cranial nerve and upper-extremity neurological function were normal. Motor strength in the right lower extremity was grade 3 for hip flexors and quadriceps, and grade 4+ for tibialis anterior, extensor hallicus longus and gastrocnemius-soleus function. Motor strength in the left lower extremity was grade 3 for hip flexors, tibialis anterior, extensor hallicus longus and gastrocnemius-soleus and grade 4- for quadriceps function. Sensation was diminished to light touch in the T12-S3 dermatome bilaterally. Patella and achilles tendon reflexes were normal. No clonus was present. A Babinski's reflex was present bilaterally and the patient had a diminished rectal tone.

Magnetic resonance imaging (MRI) demonstrated a destructive mass lesion of L1 with epidural spread resulting in severe stenosis and compression of the conus medullaris. A pathologic burst fracture was also present at L1 (Figure 1). Chest computed tomography (CT) scan demonstrated a large right chest wall heterogeneous mass measuring 153 x $135 \mathrm{~mm}$ occupying the majority of right hemithorax and exerting considerable mass effect and compression on the trachea, atelectatic right lung, right mainstem bronchi, right lobar bronchi, right pulmonary artery, and the left atrium (Figure 2).

\section{Operation and postoperative course}

The patient was taken urgently to the operating room from the ER. A laminectomy was performed from T12-L2. The dura was noted to be under significant pressure. The right superior and inferior facet of L1
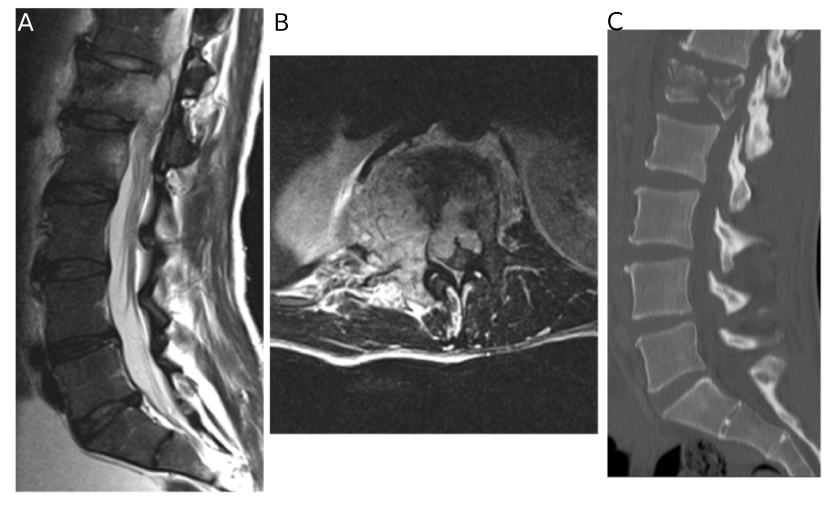

Fig. 1. (A) Sagittal T2 and (B) axial T2 MRI demonstrating a destructive mass involving $\mathrm{L} 1$ with epidural involvement resulting in severe spinal canal stenosis. (C) Sagittal CT scan demonstrating a burst fracture of L1. as well as the right L1 pedicle and transverse process were removed in order to ensure adequate exposure and decompression of the spinal canal anteriorly and minimize retraction of the spinal cord. Given the fact that the patient had not undergone a complete malignancy workup and his life expectancy could not be prognosticated at the time of surgery, the decision was made to not perform an extensive procedure such as a complete vertebrectomy with cage reconstruction. Using an extracavitary approach, the tumor was debulked and the spinal canal was decompressed anteriorly until there was no mass effect on the spinal cord. After adequate decompression was achieved, the spine was stabilized with pedicle screw and rod instrumentation at T11, T12, L2 and L3 (Figure 3). Tumor specimens were obtained for culture and histopathological review at the time of surgery.

Immediately postoperatively, a malignancy workup was initiated. Positron emission tomography-computed tomography (PET-CT) revealed a necrotic tumor originating in the mediastinum and

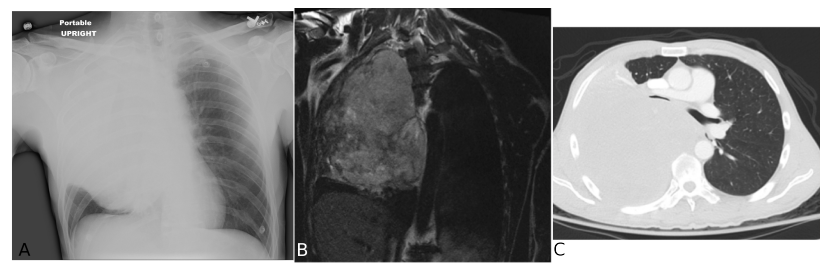

Fig. 2. (A) Anterior-posterior chest x-ray (B) Coronal T2 MRI and (C) axial CT scan demonstrating a massive lesion in the right hemithorax obliterating the right lung and exerting considerable mass effect on the airway and vascular structures.

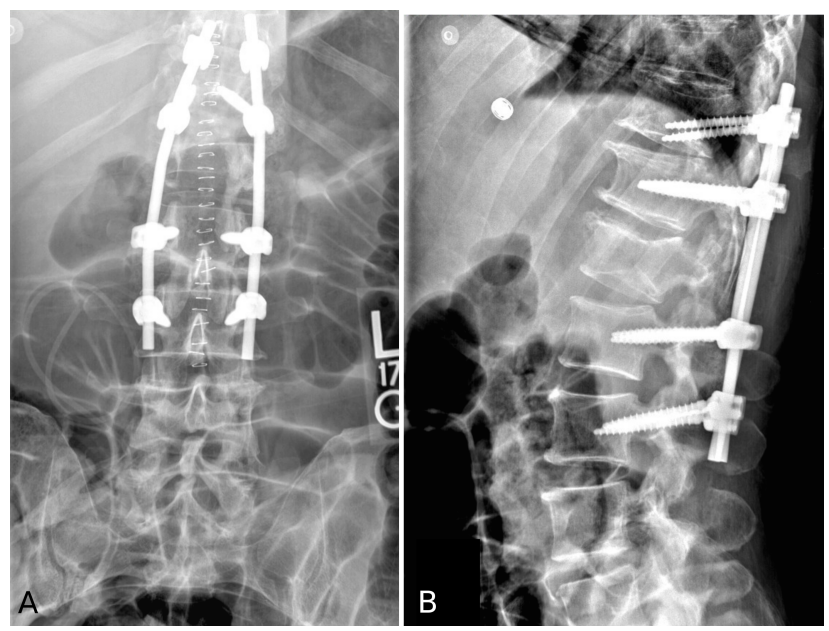

Fig. 3. C(A) Anterior-posterior and (B) lateral spine $x$-ray demonstrating pedicle screw and rod instrumentation at T11, T12, L2 and L3. 
extending towards the right hemithorax with metastasis to the right renal cortex, right inguinal canal and the thoracolumbar spine. Laboratory values showed elevated levels of alpha-fetoprotein (AFP) and betahuman chorionic gonadotropin hormone of 4770ng/ $\mathrm{mL}$ and $190 \mathrm{mIU} / \mathrm{mL}$, respectively. A scrotal ultrasound revealed no evidence of a mass lesion. Postoperatively, the patient's motor function improved to $5 / 5$ strength throughout the bilateral lower extremities. He also made a complete recovery of his bowel and bladder functions.

\section{Pathologic findings}

Microscopic examination of the tumor revealed polygonal cells with moderate amounts of clear to lightly eosinophilic cytoplasm, arranged in solid, microcystic and papillary architecture. Several foci of tumor cells oriented about small vascular profiles reminiscent of Schiller-Duval bodies were identified. Also present were intracytoplasmic hyaline globules. Immunohistochemical studies showed the tumor cells to be positive for SALL4, cytokeratins AE1/ AE3 and CAM 5.2 (Figure 4). Given the presence of the mediastinal and chest wall mass, the elevated serum AFP levels, and the histologic and immunohistochemical features, a diagnosis of a poorly differentiated malignant neoplasm consistent with yolk sac tumor was rendered.

\section{Adjuvant therapy}

Four cycles of chemotherapy consisting of ifosfamide, etoposide and cisplatin was initiated and radiation therapy was administered to the spine operative bed. After chemotherapy and radiation, his alpha-fetoprotein and beta-human chorionic go-

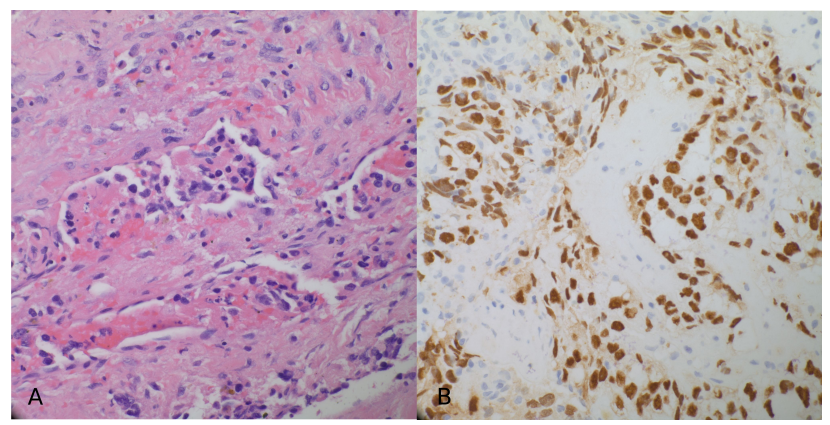

Fig. 4. (A) Histopathologic (hematoxylin and eosin) section showing polygonal tumor cells surrounding a small blood vessel (400X magnification). (B) Immunohistochemical study of tumor cells demonstrating strong nuclear positivity for SALL4 (400X magnification). nadotropin hormone normalized to $8.4 \mathrm{ng} / \mathrm{mL}$ (from $4770 \mathrm{ng} / \mathrm{mL}$ ) and $1 \mathrm{mIU} / \mathrm{mL}$ (from $190 \mathrm{mIU} / \mathrm{mL}$ ), respectively. A chest CT scan obtained approximately 3 months after surgery also confirmed an interval decrease of the right chest wall mass (Figure 5).

\section{Follow-up}

The patient was subsequently lost to follow-up 5 months from the day of presentation. It remains unclear if he his deceased or moved back to his native country of Russia.

\section{Discussion}

Metastatic cancer to the brain and spinal cord is a well-established cause of neurological dysfunction in patients with malignancies. It is estimated that 2-5\% of patients with cancer have evidence of epidural metastasis. ${ }^{2,3,4-6,10}$ Lung, prostate, and breast cancer each account for $15-20 \%$ of all cases in adults. ${ }^{2,5,6-8}$ In children, sarcomas, neuroblastomas, Hodgkin's disease, and germ cell tumors are the most common cause of epidural metastasis. ${ }^{7,9-12}$

Spinal cord compression from yolk sac tumors in children has been described in the literature., ${ }^{3,4,9,11-14}$ However, this is the first study to describe an extragonadal yolk sac tumor originating from the mediastinum of an adult male that subsequently caused an acute conus medullaris syndrome.

The anterior mediastinum is the most common site

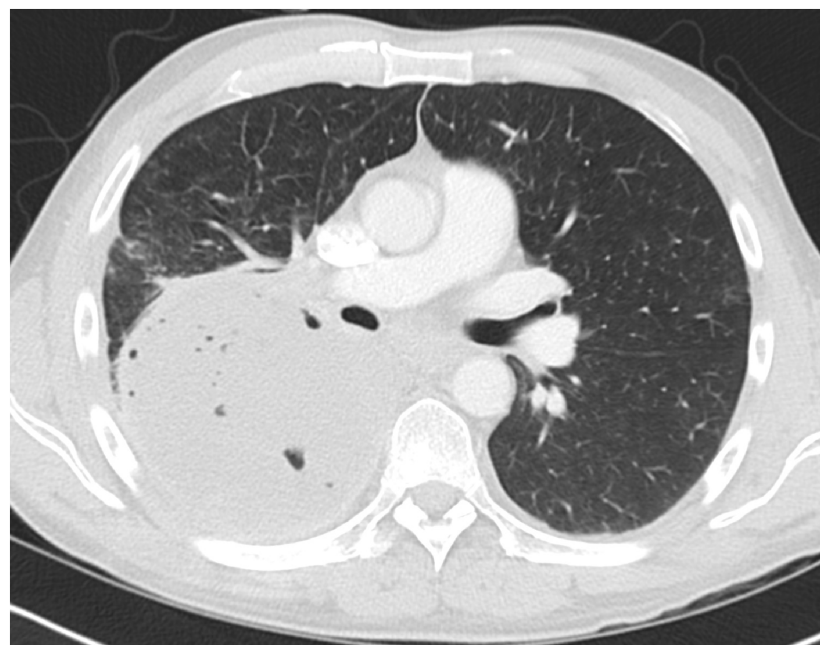

Fig. 5. Axial CT scan demonstrating an interval decrease of the right chest wall mass. 
of extragonadal germ cell tumors. Benign mature teratoma or seminoma are the most common subtype while nonseminomatous germ cell tumors (NSGCT) such as yolk sac tumors are rare. ${ }^{1,14}$ Primary mediastinal NSGCT carry a poor prognosis with $40-50 \%$ 5 -year relative survival rates after chemotherapy and surgery. The survival rate is $25 \%$ if there is evidence of metastatic disease. ${ }^{1,15}$ Primary mediastinal NSGCT has the worst survival of all extragonadal germ cell tumors due to large tumor bulk at diagnosis, resistance to chemotherapy and difficulty in removing all residual disease after chemotherapy.

In this study, we present the first case of an extragonadal yolk sac tumor originating from the mediastinum of an adult male, and metastasizing to the spine, resulting in an acute conus medullaris syndome. Urgent decompression of the neural elements followed by stabilization of the spine is paramount in relieving pain and maximizing the chance of neurological recovery. Laboratory, radiologic and histological evaluation is key in promptly establishing a diagnosis and selecting the appropriate treatment modality.

\section{References}

1. Stang A, Trabert B, Wentzensen N, et al. Gonadal and extragonadal germ cell tumours in the United States, 1973-2007. International journal of andrology. 2012;35(4):616-625.

2. Trama A, Mallone S, Nicolai N, et al. Burden of testicular, paratesticular and extragonadal germ cell tumours in Europe. Eur J Cancer.

2012;48(2):159-169.

3. Colak A, Benli K, Berker M, Onol B. Epidural metastasis of testicular yolk sac tumor: an unusual cause of spinal cord compression. Case report. Pediatric neurosurgery. 1991;17(3):139-141.

4. Loblaw DA, Laperriere NJ, Mackillop WJ. A population-based study of malignant spinal cord compression in Ontario. Clin Oncol (R Coll Radiol). 2003;15(4):211-217.

5. Barron KD, Hirano A, Araki S, Terry RD. Experiences with metastatic neoplasms involving the spinal cord. Neurology. 1959;9(2):91-106.

6. Bach F, Larsen BH, Rohde K, et al. Metastatic spinal cord compression. Occurrence, symptoms, clinical presentations and prognosis in 398 patients with spinal cord compression. Acta neurochirurgica. 1990;107(1-2):37-43.

7. Constans JP, de Divitiis E, Donzelli R, Spaziante $\mathrm{R}$, Meder JF, Haye C. Spinal metastases with neurological manifestations. Review of 600 cases. Journal of neurosurgery. 1983;59(1):111-118.

8. Helweg-Larsen S. Clinical outcome in metastatic spinal cord compression. A prospective study of 153 patients. Acta neurologica Scandinavica. 1996;94(4):269-275.

9. Klein SL, Sanford RA, Muhlbauer MS. Pediatric spinal epidural metastases. Journal of neurosurgery. 1991;74(1):70-75.

10. Raffel C, Neave VC, Lavine S, McComb JG. Treatment of spinal cord compression by epidural malignancy in childhood. Neurosurgery.

1991;28(3):349-352.

11. Kalmanchey R, Schuler D. [Neurologic complications of childhood malignancies]. Orvosi hetilap. 1994;135(32):1739-1742.

12. Pashankar FD, Steinbok P, Blair G, Pritchard S. Successful chemotherapeutic decompression of primary endodermal sinus tumor presenting with severe spinal cord compression. Journal of pediatric hematology/oncology. 2001;23(3):170-173.

13. Resnick DK, McLaughlin MR, Albright AL. Primary endodermal sinus tumor presenting with spinal cord compression. Case report. Journal of neurosurgery. 1997;86(1):151-153.

14. Lee JK, Kim SH, Kim JH, et al. Metastatic spinal cord compression of testicular yolk sac tumor. Child's nervous system: ChNS : official journal of the International Society for Pediatric Neurosurgery. 2002;18(3-4):171-174.

15. Albany C, Einhorn LH. Extragonadal germ cell tumors: clinical presentation and management. Current opinion in oncology. 2013;25(3):261-265.

\section{Disclosures}

The authors have declared no relevant disclosures.

\section{Corresponding author}

Remi M. Ajiboye, M.D. UCLA Department of Orthopaedic Surgery 1250 16th Street, Suite 2100 Santa 
Monica, CA 90404. Remi.Ajiboye@gmail.com.

Published 6 November 2015.

This manuscript is generously published free of charge by ISASS, the International Society for the
Advancement of Spine Surgery. Copyright @ 2015

ISASS. To see more or order reprints or permissions, see http://ijssurgery.com. 